\title{
VII. Observations on the change of some of the proximate principles of vegetables into bitumen; with analytical experiments on a peculiar substance which is found with the Bovey coal
}

\section{Charles Hatchett Esq. F.R.S.}

To cite this article: Charles Hatchett Esq. F.R.S. (1805) VII. Observations on the change of some of the proximate principles of vegetables into bitumen; with analytical experiments on a peculiar substance which is found with the Bovey coal, Philosophical Magazine Series 1, 21:81, 40-51, DOI: $10.1080 / 14786440508676670$

To link to this article: http://dx.doi.org/10.1080/14786440508676670

$$
\text { 曲 Published online: } 17 \text { May } 2010 .
$$

Submit your article to this journal $\square$

$$
\text { Џll Article views: } 3
$$

Q View related articles ¿ 
little mixed, but afterwards combined, which formed the colour of a fawn's beily, exceedingly beautiful. These were all the experiments I was able to make. They are sufficient to show the relation between this plant and the carthamus : its flowers give in like manner a yellow colour; and the beautiful red which they produce becomes purer in proportion as it is separated. I wish I could present results more satisfactory; but, being buffeted by circumstances, $I$ was seldom able to carry my plans into execution; and in regard to many other objects I have nothing left but regret : but I easily console myself when I reflect, that I shall be exceedingly happy if 1 can publish what $I$ have left of ten years' observations made in a field almost new.

Since this memoir was written, having had an opportunity of observing the asperula tinctoria, I remarked that its roots exhibit the same colour as those of the danais. Having put them into spirit of wine they gave also a yellow colour, but not so pure as that of the danais. I obtained the same thing from the rubia tinctorum; and I have since learned that it had been observed that these plants give two colours, according as they are treated; which still tends to confirm the analogy I have announced.

VII. Olservations on the Change of some of the proximate Principles of Vegetalles into Bitumen; with analytical Experiments on a peculiar Sulstance which is found with the Bovey Coal. By Charles Hatchetr, Esq. F.R.S.*

\section{$\S \mathrm{I}$.}

$\mathrm{O}_{\mathrm{NE}}$ of the most instructive and important parts of geology, is the study of the spontaneous alterations by which bodies formerly appertaining to the organized kingdoms of nature have, after the loss of the vital principle, become gradually converted in to fossil substances.

In some cases this conversion has been so complete as to. destroy all traces of previous organic arrangement ; but in others the original texture and form have been more of less preserved, although the substances retaining this texture, and exhibiting these forms, are often decidedly of a mineral nature. Some, however, of these extraneous fossils (as they are called) retain part of their original substance or principles, whilst others can only be regarded as casts or impressions.

r From the Tiansactions of the Riyn' Suciety of London for 3804 . 
From the animal kingdom we may select, as examples, the fossil ivory, which retains its cartilage *; the bones in the Gibraltar rock, consisting of little more than the earthy part or phosphate of lime; the shells forming the lumachella of Bleyberg, which still possess the lustre and iridescence of their original nacre; and the shells found at Hordwell in Hampshire, and in Picardy, which are chiefly porcellaneous, but more or less calcined; also the fossil echini and others so commonly found in the limestone, chalk, and calcareous grit of this island, which, although they retain their original figure, are entirely, or at least externally, formed of calcareous spar, incrusting a nucleus of flint or chalcedony. And if, in addition to these, we may be allowed to regard the more recent limestone and chalk strata as having been principally or partly formed from the detritus of animal exuviæ, we shall possess a complete series of gradations, commencing with animal substances analogous in properties to those which are recent, and terminating in bodies decidedly mineral, in which all vestiges of organization have been completely destroyed.

The vegetable kingdom has likewise produced many instances not less remarkable; and it is worthy of notice, that animal petrifactions are commonly of a calcareous nature, while, on the contrary, the vegetable petrifactions are generally siliceous $t$.

It is not, howerer, my intention here to enter into a minute discussion concerning the formation of these ex traneous fossils; I shall therefore proceed to consider other equally or perhaps more important changes, which organized bodies, especially vegetables, appear to have suffered (after the extinction of the principle of life), by being long buried in earthy strata, and by being thus exposed to the effects of mineral agents.

\section{\$II.}

The principal object I have in view is to adduce some additional proofs that the bituminous substances are derived from the organized kingdoms of nature, and especially from vegetable bodies; for although many circumstances seem to lead to the opinion that the animal kingdom has in some ineasure contributed to the partial formation of bitumen, yet the proofs are by no means so numerous, nor so

* I have also found the cartilage perfect in the teeth of the mainmoth.

$t$ Pyrites, ociraccous iron ore, and fahlertz, are also occasionally found in the forms of $x$ getable bodies.

positive. 
positive, as those which indicate the vegetable kingdom to have been the grand source from which the bitumens have been derived. But this opinion (founded upon very strong presumptive evidence), although generally adopted, is however questioned by some persons; and I shall therefore bring forward a few additional facts, which will, I flatter myself, contribute to demonstrate, that bitumen has been, and is actually and immediately formed from the resin, and perhaps from some of the other juices of vegetables.

The chemical characters of the pure or unmixed bitumens, such as naptha, petroleum, mineral tar, and asphaltum, are, in certain respects, so. different from those of the resins and other inspissated juices of recent vegetables, that, had the former never occurred but in a separate and unmixed state, no positive inference could have been drawn from their properties in proof of their vegetable origin. Fortunately, however, they have been more frequently found under circumstances which have strongly indicated the source from whence they have been derived; and much information has been acquired from observations made on the varieties of turf, bituminous wood, and pit coal, on the nature of their surrounding strata, on the vestiges of animal and vegetable bodies which accompany them, and on various other local facts, all of which tend considerably to elucidate the history of their formation, and to throw light upon this interesting part of geology.

Some instances have already been mentioned which show that fossil animal substances form a series, commencing with such as are scarcely different from those which are recent, and terminating in productions which have totally lost all traces of organization.

Similar instances are afforded by the vegetable kingdom; but, without entering into a minute detail of every gradation, I shall only cite three examples in this island, namely,

1. The submarine forest at Sutton, on the coast of Lincolnshire, the timber of which has not suffered any very apparent change in its vegetable characters*.

2. The strata of bituminous wood (called Bovey coal) found at Bovey, in Devon; which exhibits a series of gradations, from the most perfect ligneous texture, to a substance nearly approaching the characters of pit coal, and, on that account, distinguished by the name of stone coal.

3. And lastly, the varieties of pit coal, so abundant in

- Account of a submarine Forest on the Fast Coast of England, by Dr. Corres de Scrra. 1'sil. Trans. for 1799, p. 145 . 
many parts of this country, in which almost every appear ance of vegetable origin has been destroyed.

The three examples above mentioned appear to form the extremities and centre of the series; but as, from some local circumstances, the process of carbonization and formation of bitumen has not taken place in the first instance, and as these effects have proceeded to the ultimate degree in the last, it seems most proper that we should seek for information, and for positive exidence, in the second example, which appears to be the mean point, exhibiting effects of natural operations, by which bitumen and coal have been imperfectly and partially formed, without the absolute obliteration of the original vegetable characters; and althongh I have selected the Buvey coal as an example, because it is found in this country, we must recollect that similar sub. stances, or strata of bituminous wood, are found in many parts of our globe; so that the example which has been more immediately chosen is neither rare nor partial *.

The nature, however, of the various kinds of bituminous wood may in some respects be different; but this I have not as yet had the means of ascertaining: I shall therefore only state the facts resulting from experiments made on Rovey coal, and more especially on a peculiar bituminous substance with which it is accompanied. But, before I enter into these particulars, it will be proper to mention a very remarkable schistus with which I was, some months since, favoured by the right honourable Sir Joseph Banks.

\section{\&III.}

This schistus was found by Sir Joseph in the conrse of his tour through Iceland, near Reykum, one of the great spouting hot springs, distant about twenty-four English miles from Hafnifiord; but circumstances did not permit him to ascertain the extent of the stratum.

The singularity of this substance is, that a great part of it consists of leaves, which are evidently those of the aider, interposed between the different lamellæ. I do not mean mere impressions of leaves, such as are frequently found in many of the slates, but the real substance, in an apparently half-charred szate, retaining distinctly the form of the leaves and the arrangement of the fibres.

The schistus is light, brittle, of easy exfoliation; in the transverse fracture carthy, and of a pale brown colour, but

* Strata of bituminous wond are found in various parts of France, in the vicinity of Cologne, in Hesse, Bohema, Saxony, Italy, and especially in Ireland, whore it is known under die name of surrusbrand.

when 
when longitudinally divided, the whole surface constantly presents a series of the leaves which have been mentioned, uniformly spread, and commonly of a light gray on the upper surface, and of a dark brown on the other; the fibres on the light gray surface being generally of a blackishbrown, which is also the colour assumed by the schistus when reduced to powder.

The leaves appeared to be in the state of charcoal, by being extremely brittle, by the blackish brown colour, by deflagrating with nitre, by the manner of burning, and by form. ing carbonic acid. I was, however, soon convinced that the substance of these leaves was not complete charcoal; but might more properly be regarded as vegetable matter in an incipient state of carbonization, which, although possessed of many of the apparent properties of charcoal, still retained a small portion of some of the other principles of the original vegetable.

My suspicion was excited, partly by the odour produced during combustion, which rather more resembled that of wood than that of charcoal, and partly by the brown solution formed by digesting the powder of the unburned schistus in boiling distilled water; for by various tests 1 ascertained that the substance thus dissolved was not of a mineral nature. In order, however, fully to satisfy myself in this respect, I digested 250 grains of the pulverized schistus with six ounces of water.

The liquor was, as before, of a dark brown colour.

It had hut little flavour.

Prussiate of potash, muriate of barytes, and solution of isinglass; did not produce any effeet; nitrate of silver formed a very faint cloud; sulphate of iron was slowly precipitated, of a dark brownish colour; and muriate of tin produced a white preeipitate.

A portion of the solution, by long exposure to the air, was partially decomposed; and a quantity of a brown stibstance was deposited, which could not again be dissolved in water.

Another portion was also evaporated to dryness, and afforded a similar brown substance, which was only par: tially soluble in water; and the residuum, in both of the above cases, was found to be insoluble in alcohol and in tether.

When burned it emitted smoke with the odour of vegetable matter.

250 grains of the schistus afforded about three grains of the above substance; and, when the properties of the 
aqueous solution are considered, such as its partial decomposition, and the deposit which it yielded by exposure to air, and by evaporation; the insolubility of this deposit when again digested with water, alcohol, or ether; the smoke and odour which it yielded when burned; and the precipitates formed by the addition of sulphate of iron and muriate of tin to its solution; when these properties, I say, are considered, there seems much reason to conclude, that the substance dissolved by water was vegetable extract, which had apparently suffered some degree of modification, but not sufficient to annul the more prominent characteristic properties of that substance.

The powder of the schistus which had been employed in the preceding experiment, was afterwards digested in alcohol during two days ; and a pale yellow tincture was thus formed, which, by evaporation, left about one grain of a yellow transparent substance, possessing the properties of resin.

It appears, therefore, that a substance very analogous to vegetable extract, and a small portion of resin, remain inherent in the leaves of this remarkable schistus.

As solution of ising!ass did not produce any effect, there was reason to conclude that the aqueous solution above mentioned did not contain any tannin; but, as the tannin might be combined with the alumina of the schistus, I digested a portion of it in muriatic acid, which, after filtration, was evaporated almost to dryness, leaving, however, the acid in a slight excess. This was diluted with water, and afforded a blue precipitate with prussiate of potash, a yellowish precipitate witis ammonia, and a white precipitate with muriate of tin, but not any with solution of isinglass. The tannin which might have been contained in the recent vegetable appears therefore to have been dissipated or decomposed, with the greater part of the other vegetable principles, excepting the woody fibre reduced to the state of an imperfect coal, and the small portions of extract and resin which have been mentioned.

Previous to having made the analysis, I had an idea that this schistus might be a lamellated incrustation, formed by the tufa of the hot springs ; but, according to Mr. Klaproth's analysis*, the tufa of Geyser is composed of,

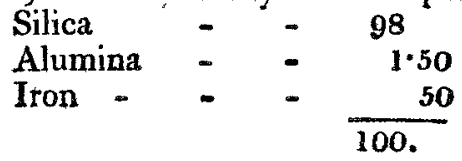

* Beiträge; Zzveiter band, p. sog. 
It is therefure very different from the schistus, the component ingredients of which were ascertained by the following analysis.

\section{Analysis of the Sehistus from 1celand*.}

A. 250 grains, by distillation, yielded water, which, in the latter part of the process, became slightly acid and turbid, $=42.50$ grains.

B. The heat was gradually increased, until the bulb of the retort was completely red hot. During the increase of the heat, a thick brown oily bitumen eame over, which weighed 7.50 grains; it was attended with a copious production of hydrogen, carbonated hydrogen, and carbonic acid, the whole of which may be estimated at 23.75 grains.

C. The residuum was black, like charcoal, and weighed 176.25 grains; but, being exposed to a strong red beat in a crucible of platina, it burned with a faint lambent flame, and was at length reduced to a pale brown earthy powder, which weighed 122 grains; so that $54 \cdot 25$ grains were consumed.

D. The 122 grains were mixed with 240 of pure potash and, as some particles of charcoal remained, 50 grains of nitre were added, and the whole was strongly heated, during half an hour, in a silver crucible. The mass was then dissolved in distilled water; and muriatic acid being added to excess, the hiquor was evaporated to dryness, and was again digested with muriatic acid much diluted; a quantity of pure silica then remained, which, after having been exposed to a red heat, weighed 98 grains.

E. The liquor from which the silica had been separated was evaporated nearly to dryness, and added to boiling lixivium of potash; after the boiling had been continued for about one hour, the liquor was filtrated, and a quantity of oxide of iron was collected, which amounted to 6 grains.

F. Solution of muriate of ammonia was added to the preceding filtrated liquor; and the whole being then heated, a copious precipitate of alumina was obtained, which, after having been made red hot, weighed 15 grains.

Carbonate of soda caused the preceding liquor (after the separation of alumina) to becone slightly turbid, but not any precipitate could be collected.

* The remaining specimens are now in the British Museum, and in the collection of the right honourable Charles Greville, 
By this analysis, 250 grains of the schistus afforded,

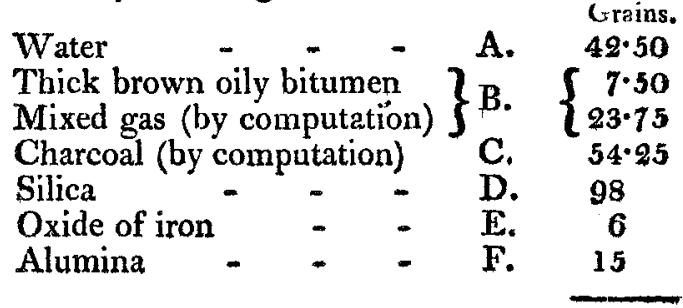

247

But the water and vegetable matter must be regarded as extraneous; and if they are deduced, the real composition of the schistus is nearly as follows:

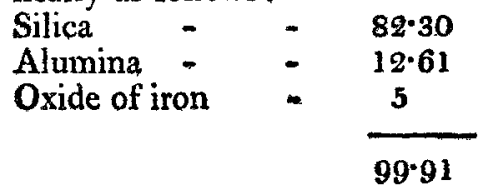

It evidently, therefore, belongs to the family of argillaceous schistus, although the proportion of silica is more considerable than has been found in those hitherto subjected to chemical analysis.

This schistus has not been noticed by Von Troil, nor by any of those who have written concerning Iceland; for the slate which was sent to protessor Bergmann by the former, and which is mentioned by the latter in one of his letters, is there expressly stated to be the common aluminous slate containing impressions *.

\section{\& IV.}

From the experiments which have been related, we find that the leaves contained in the Iceland schistus, although they are apparently reduced almost to the state of charcoal, nevertheless retain some part of their original proximate principles; namely, extract and resin. This, of itself, is

- Letters on Iceland, by Uno von Troil, p. 355.

Mr. Faujas St. Fond has, however, described a schsitus nearly similar, which is found near Roche-Seauve, in the Vivarais. The stratum cxtends about two leagues; and the only difference is, that, according to $\mathrm{Mr}$. St. Fond, the schistus at Roche-Seauve is of the nature of marle, or, as he terms it, argillo-calcareous, whereas this of Iceland is undoubtedly argillaceous. From Mr. Fond's account, it does not appear that the vegetable leaves contained in the schistus of Roche-Seauve have been chemically examined。 Essai de Geologje, par B. Faujas St. Fond, tom. i. PP. 128 and 34. 
undoubtedly a remarkable fact ; but if it were unsupported by any other, the only inference would be, that the schistus was most probably of very recent formation, and had been produced under peculiar circumstances.

I was desirous, therefore, to discover some similar cases which might serve as additional corroborative proofs of the gradual alterations by which vegetable bodies become changed, so as at length to be regarded as forming part of the mineral kingdom; and from the reasons which have been stated in the commencement of this paper, as well as from a certain similarity in the external characters of the substance composing the leaves above mentioned with those of the Bovey coal, I was induced to make this last also a subject of chemical inquiry.

In the Philosophical Transactions for the year 1760 *, some remarks on the Bovey coal, and an account of the strata, are stated, in a letter from the Rev. Dr. Milles to the Earl of Macclesfield. The object, indeed, of the author was to establish that this and similar substances are not of vegetable but of mineral origin; and, to prove this, he adduces a great number of cases, most of which, however, in the present state of natural history and of chemistry, must be regarded as proving the contrary; whilst others, mentioned by him, such as the Kimmeridge or Kimendge coal, are nothing more than bituminous slates, and of course are of a very different nature.

Dr. Milles's account of the varieties of the Bovey coal, and of the state of the pits at that time, appears to be very accurate ; and for the present state, or at least such as it was in 1796 , I shall beg leave to refer to a paper of mine, published in the fourth volume of the Transactions of the Limnean Society 1 ; for, as this is more immediately a chemical investigation, I wish to avoid, as much as possible, entering into any minute detail of geological circumstances.

It may however be proper to observe, that the Bovey coal is found in strata, corresponding in almost every particular with those of the surturbrand in Iceland described by von Troil $t$ and by Professor Bergmann $\S$. The different strata of bokh these substances are likewise similar, being composed of wood or trunks of trees, which have completely lost their cylindrical form, and are perfectly flattened,

* Vol. li. p. 534 .

+ Observations on bituminous Suhstances, p. 138.-See also Parkin* son's Organic Remains of a former World, vol. i. p. $x=6$.

* Von Troil's Letters, p. 42.

- Opuscula Bergmanni, wom. iii. De Productis Polcanicis, p. 239. 
as if they had been subjected to an immense degree of pressure *.

The Bovey coal is commonly of a chocolate-brown, and sometimes almost black. The quality and texture of it are various in different strata : from some of these it is obtained in the form of straight flat pieces, three or four feet in length, resembling boards, and is therefore called Board coal. Others have an oblique, wavy, and undulating texture, and, as Dr. Milles observes, have a strong resemblance to the'roots of trees, from which, most probably, this sort has in a great measure been formed.

Some kinds also appear to be more or less intermixed with earth ; but that which produces the most powerful and lasting fire is called stone coal : it is black, with a glossy fracture; has little or none of the vegetable texture; is more solid and compact than the others, being almost as heavy as some of the pit coals, the nature of which it seems very nearly to approach.

For chemical examination I selected some of the coal

* Bergmann, in the dissertation above quoted, accurately describes this appearance of the surturbrand, and then says, "Quze autem immanis requiritur vis, ut truncus cylindicus ita complanetur? Nonke antea particularum nexus putredinis quodam gradu fuert relaxatus? Certe, nisi compages quodammodo mutatur, quodlibet pondus incumbens huic effertui etir imprar. Ceterùn idem observatur phænomenon in umui scbisto argillaceo." This is certainly a very curious fact; and the learned Pro. fessor, with his usual acutencss; rejects the idea that mere weight can have been the cause. As a further proif also, he afterwards observes, "Orthoceratitx, qux in strato calca eo conicam figuram perfecte servant, in schisto planum fere triangulare compressione efficiznt. Idern valet de piscibus, conchis, insectisque petrefactis." And again, "Observatu, quoque dignum est, quod idim riperiatur effectus, quamisis stratum cal-

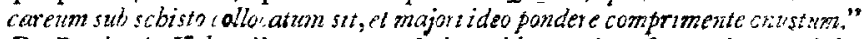
De P.ochustis Volcaniss, p. 240. It is evident, therefore, that weight alone has not produced this effect; and Bergmann's idea, that the solidity of the vegerable bodies may have undergone some previous change, in the manner of incipient putrafaction, by muisture, and by becoming heated in the mass, must oc allowed to be very probable. But bodies such as shells could not be thus affected; and therefore they raust have been exposed to some mechanical effect peculiar to argillaceous strata; which effect, however, from the circumstances which have been adduced, evidently could not have resulted from the mere pressure of the superincumbent strata. To me, therefore, it seems not very improbable that, togtther with a certain change in the solidity of vegetable bodies, produced in the manner imagined by Bergmann, and, together with some degree of superincumibent pressure, a real and powerful mechanical action has been exerted, by the contraction of the argillaceous strata, in consequence of desiccation; this, I believe, has not hitherto been much con. sidered; but I am inclined, from many circumstances, to attribute to it a very great degree of power.

Vol.21. No. 81. Fel. 180.5. D

which 
which had a wavy texture, and rather a glossy fracture; the quality of this sort being apparently intermediate between the others, as it retains completely the marks of its vegetable origin, while, at the same time, it possesses every perfect character of this species of coal.

A. 200 grains of the Bovey coal, by distillation, yielded, Grain:

1. Water, which soon came over acid, and afterwards turbid; by the mixture of some bitumen 60

2. Thick brown oily bitumen - $\quad-\quad-\quad-21$

3. Charcoal - - $-\quad$ - $\quad-\quad$ - 90

4. Mixed gas, consisting of hydrogen, ) carbonated hydrogen, and carbonic $\}$ estimated at 29 acid,

200.

The charcoal, in appearance, perfectly resembled that which is made from recent vegetables. By incineration, about 4 grains of yellowish ashes were left, which consisted of alumina, iron, and silica, derived most probably from some small portion of the clay strata which accompany the Bovey coal. But it is very remarkable, that neither the ashes cbtained from the charcoal of the Bovey coal, nor those obtained from the leaves of the Jceland schistus, afforded the smallest trace of alkali *.

B. 200 grains of the Bovey coal, reduced to powder, were digested in boiling distilled water, whieh, was afterwards filtrated and examined; but I could not discover any signs of extract, or of any other substance.

C. 900 grains were next digested with six ounces of alcohol, in a very low degree of theat, during five davo. A vellowish-brown tincture was thus formed, which, by evaporation, afforded a deep brown substance, possessing all the properties of resin, being insoluble in water, but soluble in alcohol and in ether; it also speedily melted when placed on a red hot iron, burned with much flame, and emitted a fragrant odour, totally unlike the very unpleasant smell produced by burning the coal itself, or by burning any of the common bituminous substances: The quantity, however, which could be extracted from $\$ 00$ grains of the coal,

* This, as iar as relates to the Bovcy coal, has been also noticed by Di. Tilles. Phil. Trans. vol.li..p. 5;j. But wod, howeter long submerged, is not deprived of alkali, unless it has mort or loss bencon. vered into coal ; for I have, since the teading of this Paper, made some experineats on the wood of the subrierged forest at Sutton, on the coast of Lincolnsinire, and have found it to contain potash. 
by alcohol, was but small, as it did not exceed 3 grains. But this small quantity was sufficient to prove, that al though the Bovey coal does not contain any vegetable extract, like the schistus formerly mentioned, yet the whole of the proximate principles of the original vegetable have not been entirely changed; as a small portion of true resin, not converted into bitumen, still remains inherent in the coal, although the bituminous part is by much the most prevalent, and causes the fetid odour which attends the combustion of this substance.

Upon a comparison of the general external characters of the Bovey coal with those of the substance which forms the leaves contained in the Iceland schistus, a very great resemblance will be observed; and this is further confirmed by the similarity of the products obtained from each of them in the preceding experiments, with the single exception that the leaves contain some vegetable extract, which I could not discover in the Bovey coal. They agree however in every other respect; as they both consist of wondy fibre in a state of semicarbonization, impregnated with bitumen, and a small portion of resin, perfectly similar to that which is contained in many recent vegetable bodies; and thus it seems, that as the woody fibre, in these cases, still retains some part of its vegetable characters, and is but partially and imperfectly converted into coal, so, in like manner, some of the other vegetable principles have only suffered a partial change. Undoubtedly there is every reason to believe that, next to the woody fibre, resin is the substance which, in vegetables passing to the fossil state, most powerfully resists any alteration; and that, when this is at length effected, it is niore immediately the substance from which bitumen is produced. The instunces which have been mentioned corroborate this opinion; for the vegetable extract in one of them, and more especially the resin which was discovered in both, must be regarded as part of those principles of the original vegetables which have remained, after some other portions of the same have been modified into bitumen.

The smallness of the quantity of resin obtained in both the preceding cases by no means invalidates the proof of the above opinion; but, as an additional confirmation of it, I shall now give an account of a very singular substance, which is found with the Bovey coal.

[To be continued.] 